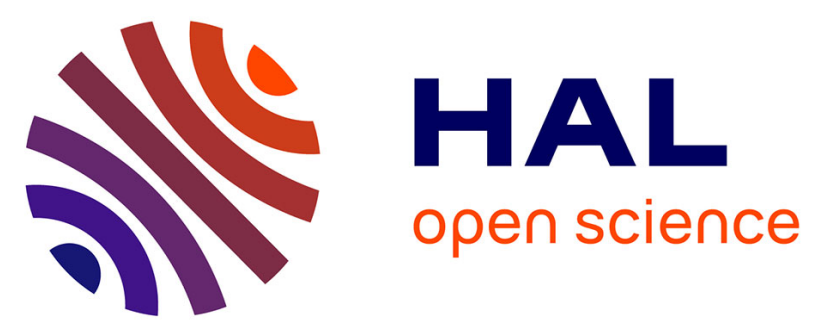

\title{
Evaluation of short food-frequency questionnaires to assess the dietary pattern associated with atherosclerotic cardiovascular diseases
}

B Noury-Desvaux, F Congnard, B Quertier, F Paillard, Guillaume Mahé

\section{- To cite this version:}

B Noury-Desvaux, F Congnard, B Quertier, F Paillard, Guillaume Mahé. Evaluation of short food-frequency questionnaires to assess the dietary pattern associated with atherosclerotic cardiovascular diseases. JMV-Journal de Médecine Vasculaire, 2018, 43 (5), pp.283-287. 10.1016/j.jdmv.2018.06.003 . hal-01880080

\section{HAL Id: hal-01880080}

\section{https://hal-univ-rennes1.archives-ouvertes.fr/hal-01880080}

Submitted on 8 Oct 2018

HAL is a multi-disciplinary open access archive for the deposit and dissemination of scientific research documents, whether they are published or not. The documents may come from teaching and research institutions in France or abroad, or from public or private research centers.
L'archive ouverte pluridisciplinaire HAL, est destinée au dépôt et à la diffusion de documents scientifiques de niveau recherche, publiés ou non, émanant des établissements d'enseignement et de recherche français ou étrangers, des laboratoires publics ou privés. 
2 Title: Evaluation of short food-frequency questionnaires to assess the dietary pattern

3 associated with atherosclerosis cardiovascular diseases.

4

5 Titre : Evaluation de questionnaires nutritionnels pour évaluer le profil alimentaire associé 6 aux maladies cardiovasculaires athéromateuses.

7

8 Authors: Noury-desvaux B. ${ }^{1}$, Congnard F. ${ }^{1}$, Quertier B. ${ }^{1}$, Paillard F. $^{2}$, Mahé G. ${ }^{2}$

91 : Institute of Physical Education and Sports Sciences (IFEPSA), Université Catholique de l'Ouest (UCO), France.

Summary

Objectives: Cardiovascular diseases are strongly related to dietary habits. Diet can be assessed using dedicated questionnaires that can be self-completed by subjects but with the risk of errors. Aims: To compare the completion error rate of two questionnaires designed to assess dietary pattern linked to cardiovascular diseases and to study the correlation between the two questionnaires. Materials and Methods: Two questionnaires were used to assess dietary patterns of students: the 14-item Food-Frequency-Questionnaire (FFQ) that was validated against biomarkers, and the Cardiovascular-Dietary-Questionnaire 2 (CDQ2), which is a 19item-FFQ derived from the previous 14-item FFQ. Both questionnaires assessed the intake of various food groups associated with either favourable or unfavourable effects on cardiovascular risk. A global dietary score was calculated for each questionnaire. Results: FFQ and CDQ2 were completed by 150 sport degree students. In the case of FFQ, 111 
$(0.7 \%)(p<0.001)$. The correlation coefficient between the overall CDQ2 score and the FFQ dietary score was $0.53(\mathrm{p}<0.01)$. Conclusion: The self-completion of CDQ2 compared to FFQ was associated with far less errors. There was a significant correlation between CDQ2 and FFQ. Preference should be given to CDQ2 in clinical practice and in studies where dietary pattern are evaluated without any interviewer.

Key words: cardiovascular disease; questionnaire; diet; atherosclerosis

Résumé

Objectifs : Les maladies cardiovasculaires sont liées aux comportements alimentaires. L’alimentation peut être évaluée par des questionnaires dédiés qui peuvent être remplis seuls mais avec un risque d'erreurs. Les objectifs sont de comparer les erreurs lors du remplissage de deux questionnaires développés pour évaluer l’alimentation liée aux maladies cardiovasculaires athéromateuses et d'étudier la corrélation entre ces deux questionnaires. Matériels et Méthodes : Deux questionnaires ont été utilisés pour évaluer l'alimentation d'étudiants : un court questionnaire de 14 questions (FFQ) qui a été préalablement validé contre des biomarqueurs et un second questionnaire (CDQ2) de 19 questions dérivées du premier questionnaire (FFQ). Les deux questionnaires évaluent des groupes alimentaires qui ont des effets favorables et défavorables sur le risque cardiovasculaire. Un score global alimentaire était calculé pour chaque questionnaire.

Résultats : Les deux questionnaires ont été remplis par 150 étudiants en faculté de sport. Pour le FFQ, 74 \% (n=111) des questionnaires étaient incomplets comparativement à 0,7\% (n=1) pour le CDQ2 ( $\mathrm{p}<0.001)$. Le coefficient de corrélation entre les scores globaux du CDQ2 et du FFQ était de 0,53 ( $<$ 0.01). Conclusion : L’auto-remplissage du CDQ2 est associé à un moindre nombre d'erreurs. Il existe une corrélation significative entre les deux questionnaires. Le CDQ2 devrait être préféré en pratique clinique et dans les études où l'alimentation est évaluée sans interviewer. 
Mots clés : Alimentation, athérosclérose, questionnaire, maladies cardiovasculaires

\section{4}

5

\section{.}

7

8

\section{ABBREVIATIONS}

14-item FFQ: 14-item Food Frequency Questionnaire

CDQ2: Cardiovascular dietary questionnaire 2

GS: Global score

MUFA: Mono Unsaturated Fatty Acids

PUFA: Poly unsaturated Fatty acids

SFA: Saturated fatty acids

VDS: Vascular dietary score

\section{INTRODUCTION}

Several studies have shown that diet is a risk factor in cardiovascular diseases[1-4].

Public policies adopted by high-income countries promoting healthier life styles and healthy

1 eating based on a Mediterranean diet should help to decrease the cardiovascular mortality[5].

2 Lifestyles are often acquired during the first part of subject's life and the effect of lifestyle is

3 related to exposure time. In this context, questionnaires could be used to assess the subjects'

dietary pattern.

5 Numerous tools with potential application to dietary assessment in clinical settings have been

6 reported[6]. All these tools do not report the same dietary information (fat intake, with or

7 without other nutrients, adherence to the Mediterranean diet, or fruit and vegetable intake).

78 The questionnaires used presented in this study has been developed specifically in France and 
reports quality diet[7]. A short questionnaire on foods related to vascular risk, comprising 14 questions (14-item FFQ) was validated against biological markers and a 7-day food survey[7]. A connection between vascular diseases and a risk-related diet had already been highlighted in cases of myocardial infarction, lower limb arterial disease and ischemic stroke[7-12]. Using this questionnaire, the scores for different food groups linked with cardiovascular diseases can be calculated[7,9,13]. In previous studies, the food evaluation was carried out with an interviewer, who ensured that all of the questions were answered. In fact, a missing answer meant that the corresponding food score could not be calculated. The fact that an interviewer was required precluded the widespread use of this questionnaire. Furthermore, this questionnaire included several open questions that could raise issues. A new questionnaire (Cardiovascular Dietary Questionnaire 2; CDQ2) based on the 14-item FFQ was therefore developed to rule out open responses and includes only closed answers.

We assume that CDQ2 generates fewer errors than FFQ when self-completed and that there is a satisfactory correlation between the two questionnaires. The primary objective of this study was to compare the number of correctly completed questionnaires and the secondary objective was to study the correlation between these two questionnaires.

\section{MATERIALS AND METHODS}

This is a transversal study carried out at the Catholic University of the West (UCO, Angers, France) involving a student cohort studying Sports, Exercise Science and Technology Degree (STAPS).

\section{Study cohort}

All students were enrolled at the Institute of Physical Education and Sports Sciences (IFEPSA-UCO, Angers) between 2014 and 2015. Students in the second and third year of their licence studies (BSc/BA), aged 18 years old and over, with or without a disorder were 
104 included. This study was approved by our institutional review board (CHU Angers). All of the

105 subjects signed an informed consent form in order to take part in the study. The study 106 protocol was conformed to the ethical guidelines of the 1975 Declaration of Helsinki.

\section{Study protocol}

108

The study was presented to the students in a lecture theatre. Two visits were then organised: the first to obtain consent and to complete the FFQ and CDQ2 questionnaires, and the second to correct any errors made on completing the questionnaires.

14-item FFQ: this questionnaire was used to assess the consumption of Saturated Fatty Acids (SFA), Mono-Unsaturated Fatty Acids (MUFA), Polyunsaturated Fatty Acids (PUFA) (omega 3 and omega 6), fruits and vegetables[7]. It was also used to calculate a global vascular risk dietary score called the Vascular Dietary Score (VDS). This score was calculated by adding up the beneficial elements (fruits and vegetables, MUFA, PUFA-n3) and subtracting the SFA score. The latter ranged from -17 to +19 . The higher the VDS, the higher the cardiovascular protective diet and vice-versa. The FFQ had a good reproducibility amongst the student population [14]. A VDS $\leq-1$ is considered as an unfavourable vascular diet. The optimal dietary score is a VDS $\geq 8$ [11]. For more information about the scoring, readers can refer to previous publications $[7,10]$

CDQ2 (Supplemental materials): This questionnaire was derived from the 14-item FFQ [7]. The 19 questions, including 2 on alcohol consumption, did not contain any open questions. The CDQ2 was used to calculate a global score (GS). The GS ranges from -36 to +47 . The higher the GS, the higher the cardiovascular protective diet and vice-versa. The scoring method is describe in the online supplemental materials. 
129 Error types: different types of errors were considered: no response, double or triple response

130 or confused response indicating the subject's inability to answer the question independently

131 (problem about the type of oil chosen, type of margarine, etc.).

132

133 Statistical analyses

134

A "Shapiro Wilk" normality test was checked to confirm normal data distribution. It showed that variables in the vascular dietary score (VDS), the global score and global score without alcohol followed a normal distribution. The number of errors in the two questionnaires was compared using the "McNemar Test". In order to investigate the

138 relationship between the two questionnaires, correlation tests were carried out between VDS obtained with the 14-item FFQ and the GS obtained with the CDQ2. The level of significance was set at $\mathrm{p}<0.05$.

\section{RESULTS}

\section{Study cohort characteristics}

Overall, 150 subjects were enrolled in our study (Table 1). The students had a mean

144 VDS of $-0.93( \pm 3.33)$ and a GS of $0.89( \pm 5.97)$

\section{FFQ error types}

In Table 2, the types of errors made by the students are presented according to six categories: omitted answers, problems with the type of oil, chips, margarine, responses in duplicate or triplicate and questions about nut consumption. This type of error recurred

151 regularly for the same questions, namely $6,7,9,12,13$ and 14 . Frequent errors were made 152 when answering questions 13 and 14 on oil and margarine consumption on the 14-item FFQ. 


\section{Results of incorrectly completed questionnaires}

Over $70 \%$ of the FFQ were incorrectly completed on the first occasion (111/150). Over 99\% of CDQ2 were correctly completed except for 1 student who forgot to complete half of the questionnaire.

\section{Relations between the questionnaires}

A significant relationship was found between the VDS obtained with the FFQ and the GS obtained with CDQ2 $(\mathrm{r}=0.53)(\mathrm{p}<0.01)$. The removal of the 2 questions related to alcohol did not change significantly the correlation: $r=0.54(p<0.01)$.

\section{DISCUSSION}

This study reports a great improvement in correct answers to questions and exploitable self-completed questionnaires with a rate close to $100 \%$ in this student population with the CDQ2. Furthermore, there is a good correlation of this questionnaire with the original 14-item FFQ that generates too much errors or missing answers due to the relative complexity for several subjects to answer correctly the questions related to the choice of fat and oils. However that information is a major one to calculate an informative global dietary score. Indeed the type of fat used for cooking or seasoning is one of the major nutritional determinants to influence the cardiovascular risk. A high intake of saturated and trans fatty acids increases the risk whereas mono and polyunsaturated fatty acids, in particular olive oil and omega-3 fatty acids reduce the risk $[15,16]$.

Fewer errors were made on completing the CDQ2 compared to the 14-item FFQ. The CDQ2 also had several advantages: first, it contained only closed questions - hence the questions were answered more quickly. The time taken to answer the question seemed to facilitate the students' decision [17]. Secondly, although CDQ2 had five additional questions, there were 
176 fewer possible answers (maximum of 19 items). The FFQ contained only 14 questions but 27

177 items had to be completed [7]. Several partial responses were required for the same question.

178 The results of a meta-analysis of controlled, randomised studies suggest that preference

179 should be given to shorter questionnaires[18]. Shorter questionnaires can be completed more

180 quickly, probably increasing the rate of correct responses[19]. Thirdly, CDQ2 includes

181 alcohol consumption, which was not assessed in the FFQ. The effect of alcohol on

182 cardiovascular disease is debated [20,21]. But numerous epidemiologic studies have shown

183 results in support of a protective effect of a small to moderate alcohol consumption and a

184 deleterious effect of a high consumption and/or binge drinking[22-24]. Many epidemiologic

185 studies have reported that a small to moderate alcohol consumption can be considered as a

186 favourable lifestyle characteristic. Thus the inclusion of alcohol in a dietary questionnaire is

187 important especially for cardiovascular diseases. It could be criticised that alcohol 188 consumption was not considered in the original FFQ and thus the correlation between the 2 189 questionnaires could be weakened. However this was not the case.

190 A significant, albeit moderate, correlation ( $\mathrm{r}=0.53$ ) was observed between the two global 191 scores derived from the 2 questionnaires. This moderate correlation may be explained by the 192 homogeneity of the population with few extreme dietary scores being recorded. Another sub193 study carried out by our team in a more heterogeneous population $(n=56)$ of $31 \pm 17$ years revealed a VDS of $1.04 \pm 5.08$ and a GS score of 3.59 \pm 7.92 with a higher correlation between

195 the two questionnaires: $\mathrm{r}=0.78(\mathrm{p}<0.001)$. Moreover the errors in FFQ answers represent the 196 main explanation for the alteration of the correlation, which is a strong argument in favour of 197 the preferential use of the CDQ2.

199 Limitations 
It may be questioned whether the small number of errors made by this population on completing CDQ2 can be extrapolated to older populations. However, the use of closed answers has facilitated the responses and we can assume this will be the case also for other populations. To date, it has not yet been shown that patients with cardiovascular diseases have an unfavourable GS obtained with CDQ2 whereas it has been reported that a low SDV score 205 (14-item FFQ) is associated with myocardial infarction, PAD and ischemic stroke. There are 206 ongoing studies to check that the CDQ2 global score is as well associated with these diseases.

207 To conclude, this study shows that CDQ2 is well correlated with the original validated 14208 item FFQ and generates far more correctly self-completed questionnaires, which could 209 facilitate its widespread use especially in clinical practice.

211 CONFLICT OF INTEREST: The authors declare that they have no conflict of interest.

\section{DECLARATIONS:}

213 Ethics approval and consent to participate: This study was approved by our institutional 214 review board (CHU Angers Ethical Committee). All of the subjects signed an informed 215 consent form in order to take part in the study.

216 Funding: This study was funded by Université Catholique de l’Ouest. 


\section{REFERENCES}

[1] Sofi F, Cesari F, Abbate R, Gensini GF, Casini A. Adherence to Mediterranean diet and health status: meta-analysis. BMJ 2008;337:a1344.

[2] Lane JS, Magno CP, Lane KT, Chan T, Hoyt DB, Greenfield S. Nutrition impacts the prevalence of peripheral arterial disease in the United States. J Vasc Surg 2008;48:897-904. doi:10.1016/j.jvs.2008.05.014.

[3] Tektonidis TG, Åkesson A, Gigante B, Wolk A, Larsson SC. A Mediterranean diet and risk of myocardial infarction, heart failure and stroke: A population-based cohort study. Atherosclerosis 2015;243:93-8. doi:10.1016/j.atherosclerosis.2015.08.039.

[4] Iqbal R, Anand S, Ounpuu S, Islam S, Zhang X, Rangarajan S, et al. Dietary patterns and the risk of acute myocardial infarction in 52 countries: results of the INTERHEART study. Circulation 2008;118:1929-37. doi:10.1161/CIRCULATIONAHA.107.738716.

[5] Lim SS, Vos T, Flaxman AD, Danaei G, Shibuya K, Adair-Rohani H, et al. A comparative risk assessment of burden of disease and injury attributable to 67 risk factors and risk factor clusters in 21 regions, 1990-2010: a systematic analysis for the Global Burden of Disease Study 2010. Lancet Lond Engl 2012;380:2224-60. doi:10.1016/S01406736(12)61766-8.

[6] England CY, Andrews RC, Jago R, Thompson JL. A systematic review of brief dietary questionnaires suitable for clinical use in the prevention and management of obesity, cardiovascular disease and type 2 diabetes. Eur J Clin Nutr 2015;69:977-1003. doi:10.1038/ejcn.2015.6.

[7] Laviolle B, Froger-Bompas C, Guillo P, Sevestre A, Letellier C, Pouchard M, et al. Relative validity and reproducibility of a 14-item semi-quantitative food frequency questionnaire for cardiovascular prevention. Eur J Cardiovasc Prev Rehabil Off J Eur Soc Cardiol Work Groups Epidemiol Prev Card Rehabil Exerc Physiol 2005;12:587-95.

[8] Carsin-Mahé M, Abraham P, Le Faucheur A, Leftheriotis G, Mahé G. Simple routine assessment of dietary pattern in patients with peripheral artery disease. J Vasc Surg 2012;56:281-2. doi:10.1016/j.jvs.2012.02.059.

[9] Mahe G, Ronziere T, Laviolle B, Golfier V, Cochery T, De Bray J-M, et al. An unfavorable dietary pattern is associated with symptomatic ischemic stroke and carotid atherosclerosis. J Vasc Surg 2010;52:62-8. doi:10.1016/j.jvs.2010.02.258.

[10] Carsin M, Mahé G. [Why should vascular patients have a dietary assessment?]. J Mal Vasc 2010;35:17-22. doi:10.1016/j.jmv.2009.11.003. 
[11] Mahe G, Carsin M, Zeeny M, De Bosschere J-P. Dietary pattern, a modifiable risk factor that can be easily assessed for atherosclerosis vascular disease prevention in clinical practice. Public Health Nutr 2011;14:319-26. doi:10.1017/S1368980010001862.

[12] Froger-Bompas C, Laviolle B, Guillo P, Letellier C, Ligier K, Daubert J-C, et al. Sustained positive impact of a coronary rehabilitation programme on adherence to dietary recommendations. Arch Cardiovasc Dis 2009;102:97-104. doi:10.1016/j.acvd.2008.10.020.

[13] Antoine-Jonville S, Sinnapah S, Laviolle B, Paillard F, Hue O. Heterogeneity of dietary profiles in highly sedentary young Guadeloupean women. Int J Sport Nutr Exerc Metab 2010;20:401-8.

[14] Balquet L, Noury-Desvaux B, Jaquinandi V, Mahé G. [Good reproducibility of a 14item food frequency questionnaire for cardiovascular prevention in students]. J Mal Vasc 2015;40:18-23. doi:10.1016/j.jmv.2014.12.005.

[15] Estruch R, Ros E, Salas-Salvadó J, Covas M-I, Corella D, Arós F, et al. Primary prevention of cardiovascular disease with a Mediterranean diet. $\mathrm{N}$ Engl $\mathrm{J}$ Med 2013;368:1279-90. doi:10.1056/NEJMoa1200303.

[16] Mozaffarian D, Wu JHY. Omega-3 fatty acids and cardiovascular disease: effects on risk factors, molecular pathways, and clinical events. J Am Coll Cardiol 2011;58:2047-67. doi:10.1016/j.jacc.2011.06.063.

[17] Triantaphyllou E. Multi-criteria decision making methods: a comparative study. Dordrecht: Kluwer; 2010.

[18] Baumgartner R, Heberlin T. Recent research on mailed questionnaire response rates. Eval Res 1985:65-75.

[19] Edwards P, Roberts I, Sandercock P, Frost C. Follow-up by mail in clinical trials: does questionnaire length matter? Control Clin Trials 2004;25:31-52. doi:10.1016/j.cct.2003.08.013.

[20] Cleophas TJ. Wine, beer and spirits and the risk of myocardial infarction: a systematic review. Biomed Pharmacother Biomedecine Pharmacother 1999;53:417-23. doi:10.1016/S0753-3322(99)80121-8.

[21] Fernández-Solà J. Cardiovascular risks and benefits of moderate and heavy alcohol consumption. Nat Rev Cardiol 2015;12:576-87. doi:10.1038/nrcardio.2015.91.

[22] Hertog MG, Feskens EJ, Hollman PC, Katan MB, Kromhout D. Dietary antioxidant flavonoids and risk of coronary heart disease: the Zutphen Elderly Study. Lancet Lond Engl 1993;342:1007-11. 
[23] Sharpe PC, McGrath LT, McClean E, Young IS, Archbold GP. Effect of red wine consumption on lipoprotein (a) and other risk factors for atherosclerosis. QJM Mon J Assoc Physicians 1995;88:101-8.

[24] Sacco RL, Elkind M, Boden-Albala B, Lin IF, Kargman DE, Hauser WA, et al. The protective effect of moderate alcohol consumption on ischemic stroke. JAMA 1999;281:5360.

Table 1: Students Cohort Characteristics.

\begin{tabular}{cc} 
Characteristics & $\begin{array}{c}\text { Population } \\
(\mathrm{n}=150)\end{array}$ \\
\hline Age (years old), m +/- sd & $20+/-1$ \\
Weight (kg), m +/- sd & $67.2+/-8.9$ \\
Height (m), m +/- sd & $1.76+/-0.08$ \\
Men, n (\%) & $111(74)$ \\
Smokers, n (\%) & $28(19)$ \\
\hline
\end{tabular}

Legend : m means mean and sd means standard deviation 
Table 2: Type of errors found in the 14-item FFQ ( $\mathrm{n}=150$ participants)

\begin{tabular}{cccc} 
Questions & Missing & Multiple & \\
& answer & answers & \\
\hline Fries consumption & 7 & 22 & 63 \\
Bread and derived products & 1 & & 4 \\
Nuts consumption & & 2 & \\
Raw butter or cream consumption & & & 31 \\
Margarin consumption & 12 & & 47 \\
Oil consumption & 64 & & \\
\hline
\end{tabular}


1. How many portions of cheese do you eat on average? $\left(1\right.$ portion $=1 / 8^{\text {th }}$ of camembert $=30 \mathrm{~g})$
less than 1 portion per day
SFA score $=0 \mathrm{pt}$
1 portion per day
SFA score $=2$ pts
2 portions per day
SFA score $=4$ pts
3 or more portions per day
SFA score $=6$ pts

\section{Do you eat dairy products?}

(1 dairy product $=1$ yoghurt or $100 \mathrm{~g}$ of white cheese or 1 glass of milk $(15 \mathrm{cl})$ or 1 cream or desserts containing milk)
I only eat skimmed or semi-skimmed dairy products
SFA score $=0 \mathrm{pt}$
I do not eat dairy products or I eat less than 1 per day
SFA score $=0 \mathrm{pt}$
I eat 1 to 2 dairy products every day
SFA score $=1 \mathrm{pt}$
I eat 3 dairy products every day
SFA score $=2$ pts
I eat 4 or more dairy products per day
SFA score $=3$ pts

3. Do you eat pork, beef, veal, mutton or lamb?
0 to once a week
SFA score $=0 \mathrm{pt}$
2 to 3 times a week
SFA score $=1 \mathrm{pt}$
4 to 6 times a week.
SFA score $=2$ pts
once a day, or more
SFA score $=3$ pts 
4. Do you eat fresh, tinned or frozen fish (including tuna, mackerel, sardines and herring)?

at least once a week

once a week

twice a week

3 times a week

4 times a week or more
UFA Score $=0 \mathrm{pt}$

UFA Score $=3$ pts

UFA Score $=6$ pts

UFA Score $=9$ pts

UFA Score $=12$ pts

5. Do you eat processed and deli meats (except lean ham) i.e. ham, pâté, salami, rillettes, bacon, sausages (also in stews/casserole dishes, sauerkraut, etc.)?

0 to once a week

2 to 3 times a week

4 to 6 times a week

once a day

more than once a day
SFA score $=0 \mathrm{pt}$

SFA score $=1 \mathrm{pt}$

SFA score $=2$ pts

SFA score $=3$ pts

SFA score $=4$ pts

6. Do you eat quiches, tarts and savoury snacks (toasted sandwiches, quiches, tarts, pizza, fried foods, hamburgers, sandwiches with butter, etc.)?

0 to once a week

2 to 3 times a week

4 to 6 times a week

once a day or more
SFA score $=0 \mathrm{pt}$

SFA score $=2$ pts

SFA score $=3$ pts

SFA score $=4$ pts

7. Do you eat shop cake, gateaux and biscuits made from butter (including "homemade" produce)?

0 to 1 portion per week

2 to 4 portions per week
SFA score $=0 \mathrm{pt}$

SFA score $=2$ pts 
8. Do you eat viennoiseries (croissant, brioche, pain au chocolat, pain au lait, etc.)?
0 to 1 per week
SFA score $=0 \mathrm{pt}$
2 to 3 per week
SFA score $=1 \mathrm{pt}$
4 to 6 per week
SFA score $=2$ pts
1 per day
SFA score $=3$ pts
more than 1 per day
SFA score $=4$ pts

\section{Do you eat fresh fruit?}

(1 portion $=1$ average-sized fruit, for example 1 apple or 2 clementines or a small dish of berries/small fruit)

Never or rarely

FV Score $=0 \mathrm{pt}$

1 to 2 portions per week

FV Score $=1 \mathrm{pt}$

3 to 6 portions per week

FV Score $=2$ pts

7 to 13 portions per week (at least 1 fruit per day)

FV Score $=3$ pts

14 portions or more per week (at least 2 pieces of fruit per day) FV Score $=4$ pts

10. Do you drink fruit juice every day (pure juice without added sugar)

no or less than 1 glass per day

$$
\begin{aligned}
& \text { FV Score }=0 \text { pt } \\
& \text { FV Score }=1 \mathrm{pt} \\
& \text { FV Score }=2 \text { pts }
\end{aligned}
$$$$
\text { yes, } 1 \text { glass per day }
$$$$
\text { yes, } 2 \text { glasses or more per day }
$$

11. Do you eat cooked vegetables and vegetable soup $(1$ portion $=1$ plate or 2 bowl $)$

$$
\text { Never or rarely }
$$

$$
\text { FV Score }=0 \mathrm{pt}
$$


1 to 2 portions per week

3 to 6 portions per week (less than 1 portion per day)

1 portion per day

more than 1 portion per day
FV Score $=1 \mathrm{pt}$

FV Score $=2$ pts

FV Score $=3$ pts

FV Score $=4$ pts

12. Do you eat raw vegetables and salads?

Never or rarely

1 to 2 portions per week

3 to 6 portions per week (less than 1 portion per day)

1 portion per day on average

more than 1 portion per day
FV Score $=0 \mathrm{pt}$

FV Score $=1 \mathrm{pt}$

FV Score $=2$ pts

FV Score $=3$ pts

FV Score $=4$ pts

13. Do you usually eat margarine with a high Omega 3 content such as Fruit d'or ${ }^{\circledR}$ or Primevère ${ }^{\circledR}$ or Saint-Hubert oméga $3{ }^{\circledR}$ ?

No

yes, with 1 meal per day

yes, with 2 meals per day

yes, with 3 or more meals per day
UFA Score $=0 \mathrm{pt}$

UFA Score $=1 \mathrm{pt}$

UFA Score $=2$ pts

UFA Score $=3$ pts

14. Do you use butter on your bread or in your food?

( 1 portion = 1 individual portion of $10 \mathrm{~g}$ )

never or rarely

1 portion per day

2 portions or more per day
SFA score $=0 \mathrm{pt}$

SFA score $=2$ pts

SFA score $=4 \mathrm{pts}$

15. Do you cook with butter or with hard margarine such as Astra ${ }^{\circledR}$ ? 
never or rarely

yes, 1 meal per day

yes, 2 meals per day
SFA score $=0 \mathrm{pt}$

SFA score $=2$ pts

SFA score $=4$ pts

16. Do you usually use one of the following oils: rapeseed, soybean, nut, or Isio4 ${ }^{\circledR}$ ? no

$$
\text { UFA Score }=0 \mathrm{pt}
$$

yes, at least 1 soupspoonful per day

UFA Score $=2$ pts

yes, 1 soupspoonful per day

UFA Score $=4$ pts

yes, 2 soupspoonfuls or more per day

UFA Score $=6$ pts

\section{Do you usually use olive oil ?}

no

yes, at least 1 soupspoonful per day

yes, 1 soupspoonful per day

yes, 2 soupspoonfuls per day

yes, 3 soupspoonfuls per day

yes, 4 or more soupspoonfuls per day
UFA Score $=0 \mathrm{pt}$

UFA Score $=1 \mathrm{pt}$

UFA Score $=2$ pts

UFA Score $=4$ pts

UFA Score $=6$ pts

UFA Score $=8$ pts

18. How much alcohol do you consume Monday to Friday? - in terms of the number of glasses of alcoholic drinks per day (see the table on the right for equivalents)
never or seldom
$\mathrm{OH}$ score $=0 \mathrm{pt}$
1 glass of alcohol
$=10 \mathrm{cl}$ of Wine (i.e. 7.5 glasses in a $75 \mathrm{cl}$ bottle)
at least 1 glass per day
OH score $=1 \mathrm{pt}$
1 glass per day
$\mathrm{OH}$ score $=2 \mathrm{pts}$
$=10 \mathrm{cl}$ of Champagne
$=2$ to $3 \mathrm{cl}$ of strong aperitif (Whisky, Pernod, etc.)
$7 \mathrm{cl}$ of apéritif-Muscat, Port, Martini
2 glasses per day
$\mathrm{OH}$ score $=4 \mathrm{pts}$
$25 \mathrm{ml}$ of Beer (half) or $5^{\circ} \mathrm{Cider}$ 
3 glasses or more per day $\quad \mathrm{OH}$ score $=0 \mathrm{pt}$

19. How much alcohol do you consume at the weekend? - give the overall quantity for Saturday and Sunday

never or seldom

1 to 2 glasses

3 to 7 glasses

8 or more glasses
OH score $=0 \mathrm{pt}$

OH score $=0 \mathrm{pt}$

$\mathrm{OH}$ score $=0 \mathrm{pt}$

$\mathrm{OH}$ score $=0 \mathrm{pt}$; and a positive answer to this question cancels all points at qs 18 .

\section{CDQ 2 Scores:}

SFA (saturated fatty acid) Score: $\quad 0$ to 36

UFA (unsaturated fatty acid) Score: 0 to 29

$>$ FV (fruits and vegetables) Score: 0 to 14

$>\mathrm{OH}$ (alcohol) Score: $\quad 0$ to 4

Global CDQ2 Score: UFA + FV + OH - SFA : -36 to +47

(the higher, the better $=$ more protective) 